\title{
Advanced computer-multi-media technology and direct mental health delivery
}

\author{
D. Segal ${ }^{1} \&$ D. A. Gordon ${ }^{2}$ \\ ${ }^{1}$ Department of Behavioural Sciences, \\ The College of Management Academic Studies Division, Israel \\ ${ }^{2}$ Department of Psychology, Ohio University, U.S.A.
}

\begin{abstract}
Computer multi media rapid developing technology provides new possibilities for mental health delivery in the form of direct psycho-educational intervention and prevention with clients, as well as training professionals. It is now possible to integrate computer multi media technology and clinical interventions, and develop intervention and training programs that are efficient and involve relatively minimal or no face-to-face contact with therapists. Such interventions, unlike traditional psychotherapeutic methods, could be at low cost and quickly disseminated to clinics and social agencies. Accumulating supportive research is showing moderate to large effect sizes in using an interactive computer multi media program for addressing clinical problems. The article addresses advantages of implementing psycho-educational intervention via advanced technology in clinical practice by following the case study of the Parenting Wisely (PW) intervention program.
\end{abstract}

Keywords: multimedia, intervention, mental health, parenting, psychoeducational, parenting, technology.

\section{Introduction}

Mental health delivery structures have been significantly changing over the past few years. These changes could be attributed to; 1) theoretical paradigm shifts, 2) rising cost of mental health treatment that generates pressure to design and conduct cost-effective interventions [1], and 3) rapid technological development as more mental health professionals are getting familiar and comfortable with the opportunities embedded in the utilization of advanced technology. 
In a meta-analysis of 100 studies, McNeil and Nelson [2] found substantial effects of interactive videodisk instruction on cognitive and performance measures, with a .53 mean effect size across age groups (college students, military personnel, sales persons), instructional content, and environment. These studies were conducted in military, industrial, and higher educational settings, and they have shown that interactive videodisk instruction reduces instruction cost and time $[4,5,6]$. In addition, this form of instruction has been shown to lead to greater practice time than did other methods; users find the experience very enjoyable. Interactive videodisk instruction has been found to be more effective than traditional lectures, reading, and passive viewing of videotapes; and it produces greater effect sizes than does computer-based instruction (.69 vs. .26) $[7,8]$.

It is now possible to integrate computer-multimedia technology and clinical interventions. Such integration could mean more efficient and relatively short interventions with a low number of face-to-face contact hours with therapists. Furthermore, integrative interventions could resolve major difficulties in reaching targeted at-risk population or reaching therapeutic goals in comparison to classical therapy practice as depicted in table 1 where we summarize the differences between therapy, as practiced in community settings, and the technological approach used in interactive CD-ROM training program. Design of valid contents and procedures for intervention and professional-training programs should be thoroughly planned. Based on our experience we identified several areas for consideration for program planning:

1. Targeted change.

2. Target population.

3. Technical concerns.

4. Personnel responsible for intervention implementation.

5. Scientific considerations

6. Methods of dissemination \& further program development.

\subsection{Case study overview - the Parenting Wisely}

Throughout this article we refer to our practical experience using the Parenting Wisely interactive CD-ROM parent-training program. The program combines the powerful effects of teaching parenting skills via videotaped modelling [9] with the responsiveness of a computer program [10]. Each user's responses determine the subsequent content and feedback that he or she receives, much like an interaction with a therapist. The PW program presents the parent with nine different problem situations that are common in many families. When a problem is selected, a short video plays in which actors illustrate the problem. After the initial problem situation is presented, a screen appears that prompts the parent to select the method he or she normally uses (from a list of three solutions) to respond to the child's problematic behaviour. The parent then watches as his or her selected solution is played out in the video. After the video segment is completed, the computer provides the parent with feedback in the form of a question and answer session. This feedback prompts the parent to think about 
the response he or she chose, as well as reasons why the response was effective or ineffective. Through the question and answer sections, the parent is taught parenting skills. If an effective and adaptive method of dealing with the problem was not selected, the program prevents the parent from progressing to a new problem until the correct solution is chosen, viewed, and critiqued. After the correct solution has been chosen, a short review quiz (with feedback) is presented. This quiz allows parents to practice the newly learned skills. Upon completion of the quiz, the parent then advances to a new problem situation.

Table 1: Comparison of therapy and interactive CD-ROM.

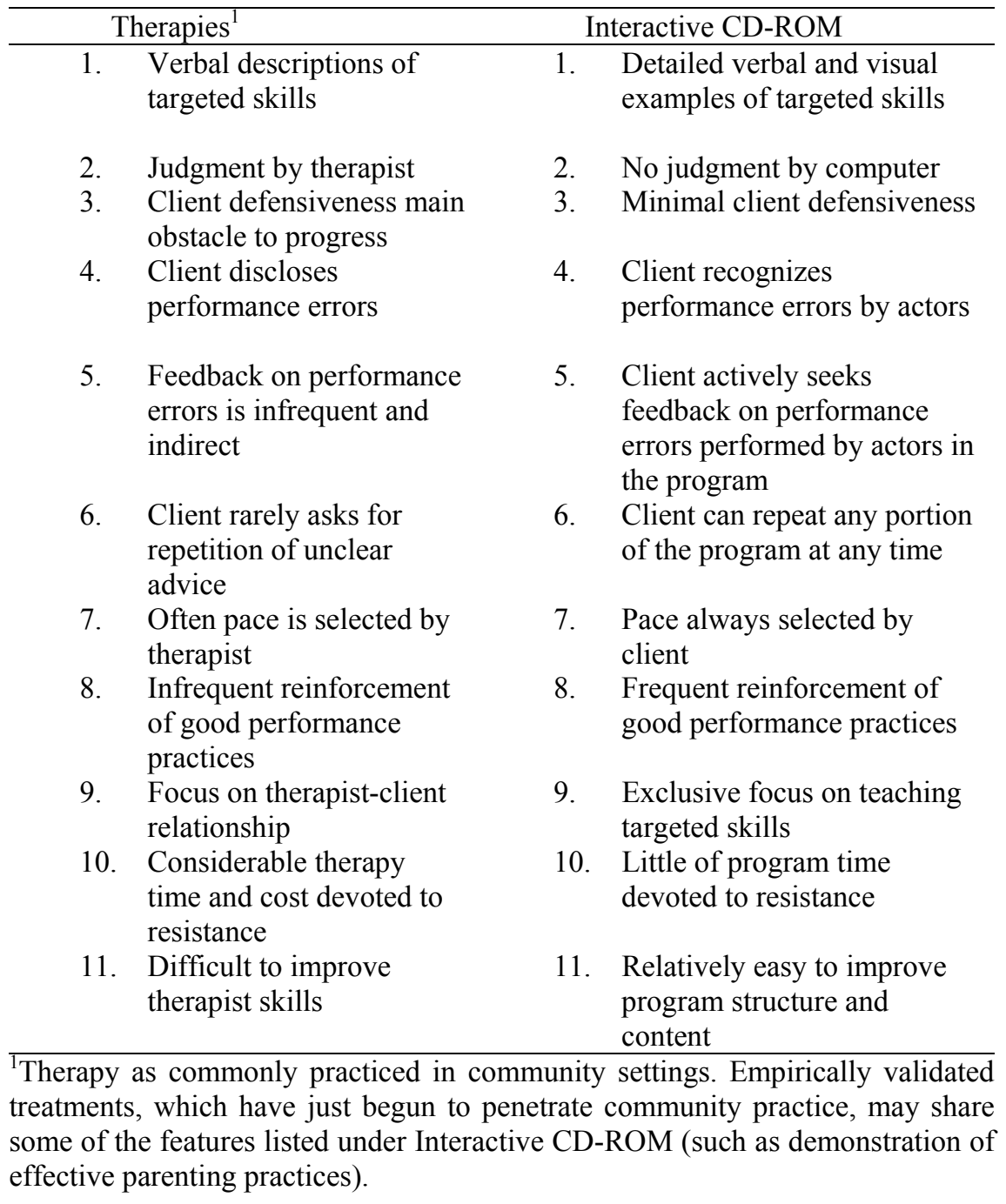




\section{The 6-point consideration protocol}

Following we address the 6 point planning protocol, based on our experience from planning, researching, implementing, and disseminating the PW program.

\subsection{Targeted change}

Interventions with cognitive-behavioural, psycho-educational, emphasis are suitable for the clinical-computer integration. In such an orientation the targeted change in clients is defined as change in knowledge, thought process, and behaviour. These areas of functioning are measurable and concrete. They could be quite easily addressed through computer technical operations.

Interactive multimedia technology allows users to determine pacing, sequence and selection of learning content. These interactive features accommodate different users' responses and permit them to choose different pathways throughout their learning process (e.g., exit any part of the program whenever they desire or choose to review other content in the program). Since this type of learning is deductively structured with enriched and contrived experience, it presumably allows learners to take responsibility for their learning [11], which in turn facilitates the learning of new material and exploration of new ideas [12].

A content validation model is depicted in figure 1, modified from Goldstein's [13] and Ford, Quinones, Sego and Sorra's [14] training evaluation models. This model could serve as a guideline for developing intervention programs. In the PW example, it consists of two dimensions: parenting skills identified from the empirical literature and parenting skills represented in the intervention program. Valid content of the program is affirmed if the intervention only contains critical and relevant skills identified from the research (i.e., intervention content relevance shown in quadrants $\mathrm{A}$ and $\mathrm{D}$ ). An intervention program would be considered content deficient or contamination if the intervention omitted crucial skills (shown in quadrant B) or included irrelevant skills (shown in quadrant C).

\subsection{Target population}

It has been argued that clients prefer to interact with a machine rather than a human therapist when instructional knowledge and its practice are a primary requirement for behavioural change [15]. This preference may be attributed to the non-judgmental nature of computers which encourages clients to learn tasks thoroughly or repeat difficult segments of content at their own pace. Nevertheless, programs should address level of education and language proficiency of prospective clients. PW was designed for use by all parents and all personnel who work with children, their parents, and their families. Because it was developed to appeal to low income families, it was written on a fifth-grade reading level. When PW's narrator option is chosen, all text is read aloud. This enables parents who cannot read, or have minimal reading ability, to benefit from the program as well.

PW is easy to use, even for those who have little or no experience with computers. In most cases, we have found that, if a staff person starts the PW 
program for the parent and shows the parent how to use the mouse, the parent is able to complete the program on his or her own. PW prompts the parent to select his or her level of computer ability. It then proceeds with instructions based on computer literacy.

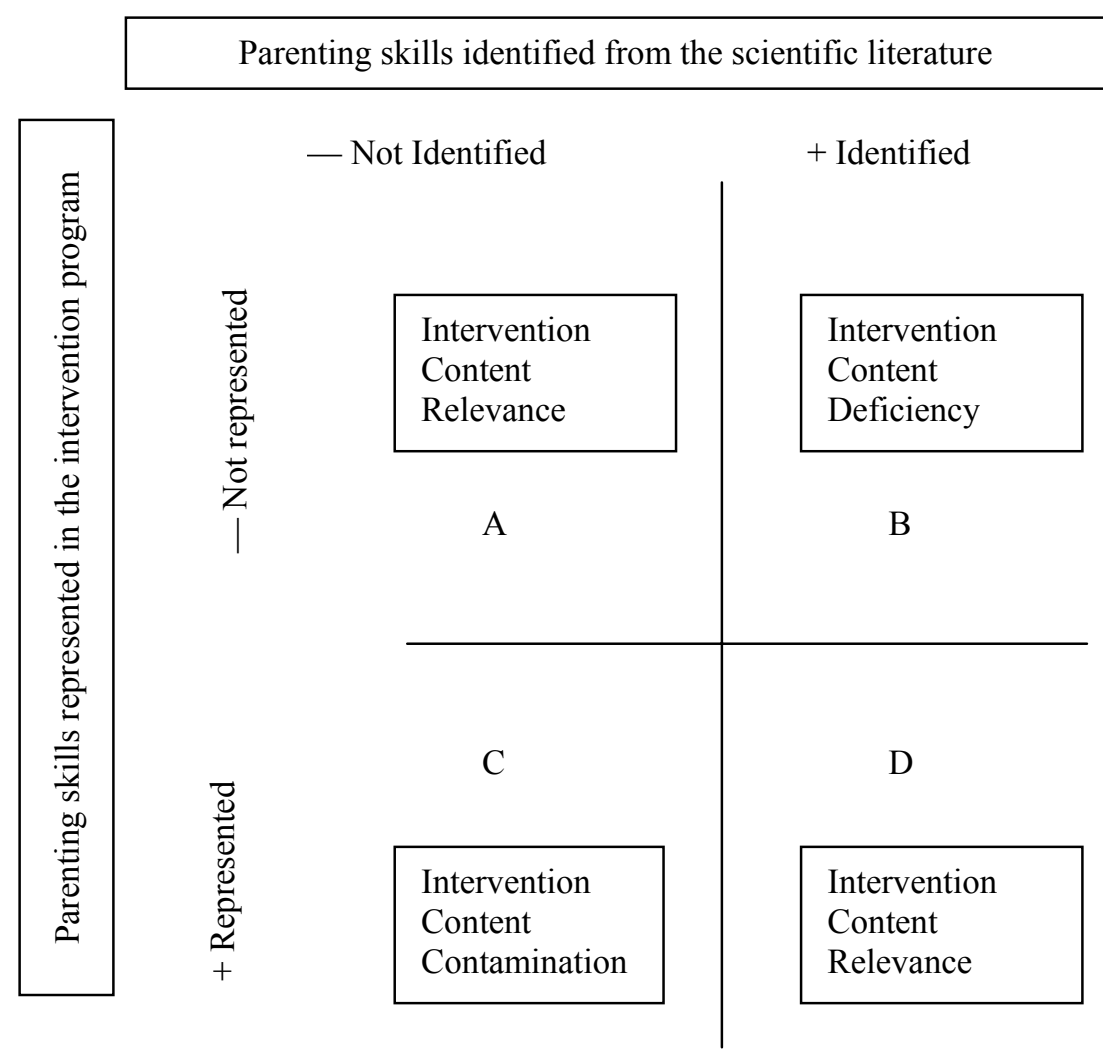

Figure 1: Conceptual content validation model.

\subsection{Technical concerns}

Rapid advances in multi-media technology have been providing us with userfriendly non-expensive software and hardware for program development. When considering development of new intervention programs one must address the cost of program development in terms of content and media. The cost will vary significantly if, for example, one includes video scenes to illustrate targeted problems or desired behaviour. Another important consideration is the cost for the end-user. In contrast to just 15 years ago, many people own computers. Intervention programs should be disseminated through social agencies where a computer can be dedicated for client use. 


\subsection{Personnel responsible for intervention implementation}

One of the main objectives in implementing psychological interventions via multi-media technology is the self-help format. Therefore, professional personnel should be minimally involved in program implementation. Their responsibility should be restricted to the basics of helping the client feel at ease with the first step with the program. Some multi-media interventions could, and maybe should, be relevant for training professionals. In both cases special technical training should be planned to minimal length and complexity.

Since we designed PW to be used by parents with little or no staff involvement (other than brief staff contact to boot up the program), training or professional experience in the use of the PW program is not required. Clinical training and experience can be useful, however. A professional with clinical experience can assess the needs of the family and tailor his or her recommendation of PW to a particular family. Clients are more likely to use a program when a trusted professional recommends it.

In addition to use by therapists, $\mathrm{PW}$ is used as the curriculum for parent education classes, as an adjunct to traditional family therapy, as curriculum for high school family living skills courses, etc. Some agencies have used PW with parents in substance abuse treatment centers and some with incarcerated parents. Courts have used PW as an alternative to other punishments. The various professionals implementing this program are counsellors, case managers, home visitors (nurses, child protective service personnel, probation officers) case workers, child care workers, extension agents, police, and teachers. Therefore, it is recommended that a program is versatile so it could be used by a variety of professionals and environments.

\subsection{Scientific considerations}

Issues such as content validation and intervention evaluation need to be meticulously addressed (e.g.; therapeutic effect and the overall human-computer interaction). Evaluation is critical with any type of intervention. A comprehensive evaluation is particularly challenging to researchers and practitioners in the discipline of human-computer interaction. Given its interdisciplinary nature, a comprehensive evaluation of human-computer interaction requires relevant (i.e., valid) and reliable criteria assessing multiple aspects such as mental abilities (e.g., effects on learning speed, recall accuracy, or reasoning), physiological capabilities (e.g., effects on visual acuity, visual field, auditory sensation), interface designs (e.g., ease of use), psychological reactions (i.e., anxiety, or resistance to technology), behavioural changes, and so on [16].

In studies we conducted, table 2, we demonstrate how the PW intervention was evaluated by three types of criteria: 1) users' reaction to the program (i.e., reaction criteria), 2) knowledge acquisition from the program (i.e., learning criteria), and 3) behaviour transfer to outside of the intervention (i.e., behaviour criteria). 
Table 2: $\quad$ Comparison of studies of Parenting Wisely.

\begin{tabular}{|l|l|l|l|l|l|}
\hline \multicolumn{1}{|c|}{ Study } & $\begin{array}{l}\text { Participants } \\
\text { (n) }\end{array}$ & \multicolumn{1}{|c|}{ Site } & Design & $\begin{array}{c}\text { Follow } \\
\text { Up } \\
\text { Period }\end{array}$ & $\begin{array}{c}\text { Child } \\
\text { Problem } \\
\text { Behaviour } \\
\text { PW Effect } \\
\text { Size }\end{array}$ \\
\hline $\begin{array}{l}\text { Cohen's } \\
\text { d) }\end{array}$ \\
\hline $\begin{array}{l}\text { Gogges \& } \\
\text { [17] }\end{array}$
\end{tabular}

= RA: Random Assignment

${ }^{2}=$ Eyberg Child Behaviour Inventory

3 = Parents Daily Report

${ }^{4}=$ Parental response to hypothetical problem behaviour

Our research studies have shown that PW is effective at reducing child problem behaviours, improving family functioning, reducing maternal depression, improving parent knowledge of positive parenting skills, and increasing parent use of such skills. In all the studies conducted on PW, parents who used the program reported overall satisfaction and found the teaching 
format easy to follow. They also found the scenarios realistic, the problems depicted to be relevant to their families, and the parenting skills taught reasonable solutions to those problems. The parents felt confident they could apply the skills in their families. These findings may help explain why parents were willing to spend two to three hours in one sitting using the program, and why improvements in child behaviour were evident a week after parents used the program.

In addition to the data we presented, we know of approximately 25 independent evaluations of PW in community settings in the US and in the UK underway currently. Continuation of supportive empirical research is critical for establishing credibility of integrated technology-intervention programs.

\subsection{Methods of dissemination and further program development}

Disseminating a psycho-educational intervention that is based on advanced technology (Level III) requires special considerations. This approach to intervention is still regarded as unusual for most practitioners in the field of psychotherapy. Many barriers block the path of even the most vigilant technology supporter (e.g. the lack of available equipment and funding to purchase, update, and maintain equipment; the lack of technological expertise; and the lack of training on how to implement the use of technology within specific fields) [23]. The use of technology among mental health providers is particularly challenging, as the mental health profession holds many views about the nature of change that must be altered for successful implementation of technological resources. Therefore, innovative programs will, most likely, be approached with some suspicion by agencies and individual clients. Therefore, dissemination requires extra effort.

Professional conferences should be actively utilized to demonstrate the technology for the purpose of exposure. Multimedia presentation in addition to the usual presentation of the program's content and research findings is highly recommended.

The internet is a viable place today for demonstration and dissemination due to its rapid data-transfer advancements. Programs should be designed to work on internet platform and as such could be considered an internet-based intervention [24] (see: www.familyworksinc.com). It is quite feasible to use governmental agencies that publish and disseminate information on mental health practices, including website listing. In our case governmental agencies such as SAMHSA, CSAP, OJJDP, and the Centers for the Application of Prevention Technologies (CAPT) were quite relevant.

An essential step to foster dissemination is continued contact with agencies that might be interested or have purchased the intervention program. By staying in contact with a variety of agencies using the program, developers can incorporate their feedback and research results into improvements to the program. This can be done regularly and inexpensively, via upgrades to the program. Changing the CD-ROM is a much less daunting task than that faced by developers of traditional programs who wish to introduce changes, following initial training, in the practices of service providers. Agencies should be asked of 
what additions to this technology they would like to see, and notify them when these improvements or new programs are available. From our experience, this feedback loop has resulted in further development and expansion of the program as well as more inquiries about it.

\section{References}

[1] Hoyt, M. F. \& Austad, C. S., Psychotherapy in a staff model health maintenance organization: Providing and assuring quality care in the future. Psychotherapy: Theory, Research, Practice, Training, 29, pp. 119 129, 1992.

[2] McNeil, B. J., \& Nelson, K. R., Meta-analysis of interactive video instruction: A 10-year review of achievement effects. Journal of Computer-Based Instruction, 18 (1), pp. 1 6, 1991.

[3] Bosco, J., An analysis of evaluations of interactive video. Educational Technology, 26, pp. 7 17, 1986.

[4] Cohen, V. B., Interactive features in the design of videodisc materials. Educational Technology, 24, pp. 16 22, 1984.

[5] Fletcher, J. D., Effectiveness and cost interactive videodisc instruction in defense training and education (Report No. P-2372). Institute for Defense Analysis, 1990.

[6] Kacir, C., \& Gordon, D.A., Parenting adolescents wisely: The effectiveness of an interactive videodisk parent-training program in Appalachia. Child and Family Behavior Therapy, 21 (4), pp. 1 22, 1999.

[7] Fletcher, J. D., Effectiveness and cost of interactive videodisc instruction in defense training and education (Report No. P-2372). Institute for Defense Analysis, 1990.

[8] Niemiec, R., \& Walberg, H.J., Comparative effects of computer-assisted instruction: A synthesis of reviews. Journal of Educational Computing Research, 3, pp. 19 37, 1987.

[9] Webster-Stratton, C., Kolpacoff, M., \& Hollinsworth, T., Selfadministered videotape therapy for families with conduct-problem children: Comparison with two cost-effective treatments and a control group. Journal of Consulting and Clinical Psychology, 56, pp. 558-566, 1988.

[10] Bosco, J., An analysis of evaluations of interactive video. Educational Technology, 26, pp. 7 17, 1986.

[11] Cohen, V. B., Interactive features in the design of videodisc materials. Educational Technology, 24, pp. 16 22, 1984.

[12] Hapeshi, K, \& Jones, D. M, Interactive multimedia for instruction: A cognitive analysis of the role of audition and vision. International Journal of Human-Computer Interaction, 4, pp. 79 99, 1992.

[13] Goldstein, I. L., Training in Organizations (3rd Ed.). Pacific Grove, CA: Brooks/Cole Publishing Company, 1993. 
[14] Ford, J. K., Quinones, M. A., Sego, D. J., \& Sorra, J. S., Factors affecting the opportunity to perform trained tasks on the job. Personnel Psychology, 45, pp. $511527,1992$.

[15] Burda, P. C., Starky, T. W., \& Dominguez, F., Computers administered treatment of psychiatric inpatient. Computers in Human Behaviors, 7, pp. $15,1991$.

[16] Faulkner, C., The Essence of Human-Computer Interaction. New York, NY: Prentice Hall, 1998.

[17] Lagges, A., \& Gordon, D. A., Use of an interactive laserdisc parenttraining program with teenage parents. Child and Family Behaviour Therapy, 21, pp. 19 37, 1999.

[18] Gordon, D. A., \& Kacir, C. D., Effectiveness of an interactive parent training program for changing adolescent behavior for court-referred parents. Unpublished manuscript, Ohio University, Athens, 1998.

[19] Kacir, C., \& Gordon, D.A., Parenting adolescents wisely: The effectiveness of an interactive videodisk parent-training program in Appalachia. Child and Family Behavior Therapy, 21 (4), pp. 1 22, 1999.

[20] Woodruff, C., Gordon, D.A., \& Lobo, T. R., Reaching high-risk families through home-based parent training: A comparison of interactive CDROM and self-help parenting programmes. Unpublished manuscript, Ohio University, 2000.

[21] Rolland-Stanar, C., Gordon, D.A., \& Carlston, D., Family violence prevention via school-based CD-ROM parent training. Unpublished manuscript, Ohio University, 2001.

[22] Segal, D., Gordon, D. A., Chen, P. Y., Kacir, C. D. \& Gylys, J., Development and evaluation of a parenting intervention program: Integration of scientific and practical approaches. International Journal of Human-Computer Interaction, 15, pp. 453 468, 2003.

[23] Gordon, D.A., \& Rolland-Stanar, C., Lessons learned from the dissemination of Parenting Wisely, A Parent Training CD-ROM. Cognitive and Behavioral Practice, 10, pp. 312-323, 2003.

[24] Gordon, D.A., Parent training via CD-ROM: Using technology to disseminate effective prevention practices. The Journal of Primary Prevention, 21, (2), pp. 227 251, 2000. 